\title{
Growth Regulators in the Technology of Reproduction of Improved Potatoes
}

\author{
Irina Pavlovna Uromova, Natalia Nikolaevna Koposova, \\ Andrey Vladimirovich Kozlov, Dmitry Aleksandrovich Shtyrlin \\ and Yuliya Yurevna Davydova
}

Minin Nizhny Novgorod Statå Pedagogical University

1, Ulyanov street, GSP-37, Nizhniy Novgorod, 603950 Russia.

http://dx.doi.org/10.13005/bbra/2074

(Received: 10 January 2016; accepted: 15 February 2016)

\begin{abstract}
The article is devoted to studying a new generation of plant growth regulators with multi-functional action that are able to simultaneously stimulate growth and development, and to increase adaptability to adverse environmental factors, as well as to influence in the future the resistance of potatoes to diseases, showing strong anti-fungi and antibacterial activity, and ensuring protection from viruses and viroids. In course of the experiment, we studied the effect of growth stimulants (HB-101, Agat-25K and Gumi20) on productivity and quality of potatoes micro plants of the early maturity varieties of domestic (the Udacha variety) and foreign (the Red Scarlet variety) selection obtained by the method of apical meristem in vitro and cultivated in greenhouses. The first spraying with these growth promoters was performed in the budding phase, the next two - with an interval of 7 days. The obtained results allow assuming perspective the use of the NV-101 and Agat-25K growth stimulants. A more substantial increase in growth and productivity, as compared to the reference group, was observed after processing domestic Udacha variety with the NV-101 stimulator, and increased resistance to late blight was ensured by a growth regulator with bio-fungicide activity Agat-25K. According to the results of enzyme immunoanalysis (EIA), the viral and bacterial infection is absent in plants in all studied variants. Thus, using growth regulators in the initial stages of the original seed is a promising method, the use of which is necessary due to the varietal characteristics.
\end{abstract}

Key words: HB-101, Agate-25K, Gumi-20, growth stimulant, growth stimulant with bio-fungicide activity, in vitro, apical meristem, biometric indicators of potatoes, potato yield, late blight.

In modern conditions, increasing efficiency of potatoes production is only possible through the use of healthy potatoes in combination with a complex of mandatory agricultural practices with biological aspect, which limits spreading infectious diseases during the vegetation season

\footnotetext{
* To whom all correspondence should be addressed.
}

and promotes greater productivity (Anisimov, 2003).

To solve this problem, it is necessary to use biologically active substances with complex action. As indicated by many authors (Zasorin et al., 2010; Lobachev, Avdienko, 2010; Sekhon and Singh, 1985; Harmey et al., 1966; Rai et al., 2011), the use of phyto regulators for potatoes has positive effect on their growth and development and enhances their genetic potential. 
The role of growth regulators today has increased dramatically, due to aggravation of contradictions between the need to use chemical substances for increasing productivity, and the harm to human health and the environment from using them. In this case, it is necessary to use environmentally friendly low-toxic preparations that are cost-effective.

Decreasing the scope of using chemicals for protecting many crops, including potatoes, promotes increased use of growth regulators with bio-fungicide activity, which not only biochemically inhibit growth of pathogens, but improve plant resistance to adverse factors as well. It also promotes the use of growth regulators that have no effect on pathogens, but stimulate growth, development and anti-stress activity, which increases their resilience (Cheremisin, Yakimova, 2011; Kozlov, 2013).

Thus, according to some researchers (Vakulenko, 2004; Zakharin, Pigorev, 2005; Ustimenko, Postnikov, 2009; Vert et al., 2005; Zhu, 2002; Divi et al., 2010; Krischna, 2003; Kagale et al., 2007) with the advent of new generation of regulators, an opportunity appeared to manage the process more efficiently, to increase plants' resistance to stress conditions in greenhouses (at high temperatures), and to improve quality and quantity of tubers.

Today we use growth regulators like epin, zircon, gumi. They do not require significant expenses for processing plants, but increase productivity and quality of improved potatoes (Uskov, 2009; Orlov, 2004; Bobrik, 2001; Tarazanov, Ignatiev, 2013). They have been studied in many works focused on plants cultivation both in the open and in greenhouses (Kirdey, Belyaeva, 2012; Petrov et al., 2002; Brian L. Rex, 1992). However, there are other growth regulators, effectiveness of which has been studied insufficiently, particularly in the system of cultivation original potatoes for obtaining improved material for varieties of various origins (domestic and imported). Therefore, studying growth regulators is an urgent task today. In this regard, our research is aimed at studying the effect of growth regulators on the productivity and the quality of meristematic plants cultivated in greenhouses.

\section{The methods}

The experimental work was performed at the biotechnology laboratory and in the greenhouse of LLC "Elitekhoz" in the Bor district of the Nizhny Novgorod region in 2013-2014. The in vitro meristematic plants of the Udacha (domestic breeding) and the Red Scarlet (foreign breeding) potato varieties belonging to the early maturity group obtained in the laboratory were used in the experiments. The original test tube material of these varieties for micro-propagation had been purchased from the collection of the All-Russian Research Institute of Potato Breeding (Moscow region).

A mixture of peat and river sand in the 3:1 ratio was used as the substrate in the greenhouse. The agrochemical characteristics of the soil were as follows: mass fraction of humus was $3.0 \%, \mathrm{pH}$ was 5.64, mobile phosphorus content was $220 \mathrm{mg} /$ $\mathrm{kg}$, and the content of exchange potassium was $162 \mathrm{mg} / \mathrm{kg}$ soil.

The experiment setup included the following variants:
1. (Reference) - without treatment;
2. Gumi-20 $-7.5 \mathrm{ml} / 5 \mathrm{l}$ of water;
3. Agat-25K $-20 \mathrm{~g} / 5 \mathrm{l}$ of water;
4. HB- $101-0.2 \mathrm{ml} / 5 \mathrm{l}$ of water.

The first treatment with the preparations was performed in the budding phase, the following two - in 7 days intervals. A knapsack sprayer was used for treatment.

The experiments were started and statistically processed in accordance with established methods (Dospekhov, 1985). The total area of the plot was $28 \mathrm{~m}^{2}$, the accounting area was $14 \mathrm{~m}^{2}$, the experiment was repeated 4 times, and the plots were located systematically. The planting pattern was $70 \times 24 \mathrm{~cm}$.

During the vegetation period, in the conditions of the greenhouse, we determined the biometric parameters of the plants, the yield, and the incidence of potato diseases. Visual assessment and viral testing of the plants were performed using the EIA method. The harvest was assessed by weighing all tubers from the plot.

During the vegetation season, the potato plants were watered as needed, and treated with the Akhtara insecticide against the Colorado potato beetle. 


\section{RESULTSAND DISCUSSION}

It has been established that not all studied growth factors had a significant impact on the productivity and the quality of the in vitro micro plants. Moreover, reaction of the varieties to processing with various growth regulators was different, too.

The use of growth regulators had a positive impact on the biometric indicators of plants (Table. 1).

Spraying with growth regulators had a positive effect on increasing the aboveground and the underground weight of micro plants in the conditions of a greenhouse. The greatest plant height $(59.2 \mathrm{~cm})$, the maximum number of stems (5.9 pcs/plant) and the weight of roots (32.8 g) were observed in the Udacha variety when HB101 was used. The use of this growth regulator on the Red Scarlet variety was less effective; however, compared to the reference variant, the increase was $16.1 \%, 29.2 \%$ and $16.2 \%$, respectively.

As the height of the main stems increased, their quantity in a bush increased, too. The greatest number of stems was noted in the variants processed with HB-101, where the excess

Table 1. Influence of growth regulators on the biometric indicators of potato plants in a greenhouse (the average values for years 2013-2014)

\begin{tabular}{lccc}
\hline Variant & $\begin{array}{c}\text { Plant } \\
\text { height, cm }\end{array}$ & $\begin{array}{c}\text { Number of stems, } \\
\text { pcs./plant }\end{array}$ & $\begin{array}{c}\text { Weight of } \\
\text { roots, g }\end{array}$ \\
\hline the Udacha variety & 48.1 & 4.1 & 26.9 \\
Reference & 50.1 & 5.1 & 30.9 \\
Agat-25K & 48.8 & 5.0 & 29.8 \\
Gumi-20 & 59.2 & 5.9 & 32.8 \\
HB-101 & 1.1 & 0.8 & 2.4 \\
HCP & & & \\
Red Scarlet variety & 48.3 & 4.0 & 25.9 \\
Reference & 50.1 & 4.9 & 28.1 \\
Agat-25K & 48.5 & 4.5 & 25.9 \\
Gumi-20 & 56.1 & 5.3 & 2.3 \\
HB-101 & 1.1 & 0.6 & \\
HCP & & & \\
\hline
\end{tabular}

Table 2. Influence of growth regulators on the productivity of potato plants in a greenhouse (the average values for years 2013-2014)

\begin{tabular}{lcccc}
\hline Variant & \multicolumn{2}{c}{ Yield } & Quantity of tubers, & Weight of \\
pcs/plant. & 1 tuber, g \\
\hline the Udacha variety & & & & \\
Reference & 304.3 & 18.3 & 6.9 & 44.1 \\
Agat-25K & 386.3 & 23.2 & 7.9 & 48.9 \\
Gumi-20 & 346.3 & 20.8 & 7.4 & 46.8 \\
HB-101 & 490.0 & 29.4 & 8.6 & 57.0 \\
HCP & 28.1 & & 0.9 & \\
Red Scarlet variety & & & & 4.9 \\
Reference & 304.6 & 18.3 & 6.8 & 47.9 \\
Agat-25K & 392.8 & 23.6 & 7.2 & 45.9 \\
Gumi-20 & 335.1 & 20.1 & 8.4 & 5.3 \\
HB-101 & 422.5 & 25.3 & 1.1 & 3.2 \\
HCP & 24.7 & & & \\
\hline
\end{tabular}


over the reference group was 43.9-32.5\%, depending on the variety. Agat-25K and Gumi-20 preparations in this experiment had a worse effect, as compared to the reference -12.5 to $24.4 \%$, depending on the variety. The Udacha variety had the greater number of stems.

Along with increasing the vegetative mass, an increase in the underground parts of plants was noted. The weight of roots during the vegetation period in all experimental variants with both varieties exceeded that in the reference variant. The greatest weight of roots that contributed to increased yield was noted in the variant that has been treated with HB-101, as compared to the reference, by 21.9 and $16.2 \%$, depending on the variety.

The results of our previous experiments (Uromova, 2009) showed that stronger root system consumed the nutrients and moisture from the soil more productively, which promoted plants' resistance to adverse environmental factors and resulted in higher productivity of potato plants.

It may be stated in general that the studied growth regulators had significant influence on development of the bush, which, in the end, determined the yield of tubers.

The analysis of the obtained data about the effect of growth regulators on the yield of micro plants in greenhouses showed that all preparations contributed to increasing the yield (Table 2). The

Table 3. Influence of growth regulators on the occurrence and the development of late blight in potato vine in the conditions of a greenhouse (the average for 2013-2014)

\begin{tabular}{ccc}
\hline Variant & Occurrence & Development \\
& rate, $\%$ &,$\%$
\end{tabular}

the Udacha variety

\begin{tabular}{lll} 
Reference & 6.1 & 4.8 \\
Agat-25K & 1.8 & 1.6 \\
Gumi-20 & 3.1 & 3.0 \\
HB-101 & 3.3 & 3.0 \\
HCP $_{05}$ & 0.9 & 1.1 \\
Red Scarlet variety & & \\
Reference & 6.2 & 5.3 \\
Agat-25K & 2.0 & 2.0 \\
Gumi-20 & 3.4 & 3.0 \\
HB-101 & 3.4 & 3.0 \\
HCP $_{05}$ & 1.2 & 0.8 \\
\hline
\end{tabular}

maximum yield increase (60.6-38.2 \%) was observed in the variant where HB-101 was used, as compared to the reference with both varieties. Efficiency of Gumi-20 in terms of increasing the yield was considerably lower (13.6 to $9.8 \%$ ).

The obtained data make it possible to state that the use of growth regulators increased the productivity of potato bushes of the studied varieties. The most effective one was HB-101, the use of which resulted in an increase by $61.0 \%$ for the Udacha variety, as compared to the reference. A lower but still significant increase was obtained with the Red Scarlet variety. The Agat-25K and the Gumi-20 preparations were less effective.

Stimulation of tuber formation resulted in increasing the reproduction factor, which was essential for cultivating potatoes. The highest reproduction rate was observed in the variants where HB-101 was used, which exceeded the reference by 24.6 to $23.5 \%$, depending on the variety. However, using HB-101 also showed a tendency to increasing the average fraction of the tubers of the studied varieties. The average weight of one tuber on these variants was $57.0 \mathrm{~g}$ and 50.3 $\mathrm{g}$, which was higher than the reference by $29.3 \%$ and $12.3 \%$, respectively. Increasing the average weight of one tuber under the action of the Agat$25 \mathrm{~K}$ and Gumi-20 preparation was insignificant for both varieties.

The results of our research showed that the HB-101 growth regulator featured high biological activity, which contributed to a more complete implementation of potatoes' genetic potential. This was manifested in increasing growth and development of plants, which allowed the plants to endure excessive moisture or drought, increase resistance to diseases and stress, and ultimately resulted in increased yield, especially for the domestic varieties.

In the process of cultivating micro plants in greenhouses, growth regulators had an effect on the yield, quantity of mini-tubers and fractional composition of the studied varieties. The highest efficiency was manifested for the Udacha variety treated with HB-101. Using this preparation for cultivating mini-tubers by the seedlings' method increased the yield by 61.0 to $38.7 \%$, the reproduction rate - by 24.6 to $23.5 \%$ and the average weight of one tuber by 29.3 to $12.3 \%$, depending on the variety. 
Out of fungal diseases, visual inspection of potato vine revealed only late blight (Table. 3). Due to the fact that we used improved micro plants obtained by the in vitro apical meristem method, no bacterial and viral diseases were detected. The results of enzyme immunoanalysis (EIA) also showed the absence of viruses in all variants of the experiment.

The lowest occurrence rate of the disease, and its development on the leaves were noted for the Udacha variety in case of using Agat-25K (70.5 to $66.7 \%$ ). In other variants, the occurrence rate and the development of the disease were higher, and amounted to $46.0-37.5 \%$, as compared to the reference. For the Red Scarlet variety, these preparations showed weaker protective action. By the years of the research, the difference in the occurrence rate and development of the disease were not so significant, since in a greenhouse, humidity is maintained by watering, and does not depend on external factors. This fact has been proved by the data obtained by other authors (Bari and Jones, 2009; Uromova et. al., 2013). Therefore, some authors (Kotikov, 2011; Filippov, 2005) insist that nowadays the aggressiveness of the Ph. infestans pathogen has significantly increased, and manifestations of late blight are seen after almost twice shorter period of liquid water drips presence on the leaves. In this regard, the number of pathogen generations during the growing season increases, which is especially expressed in the conditions of greenhouses.

It should be noted that in the years of the research, intensity of late blight development during the growing season was low, and mostly depended on the use of growth stimulants, especially those with bio-fungicide effect, and less on the varietal characteristics. The advantage of this preparation is the fact that it not only suppresses pathogens, but also enhances the immune potential of plants, and thereby increases their resistance to adverse factors. Resistance of the Udacha variety to late blight was constant during all years of the studies, only the occurrence rate and development of disease changed, which was confirmed by the data obtained in the field experiments (Uromova, 2009).

\section{CONCLUSION}

Comparing efficiency of the studied growth regulators, one can come to a conclusion about unequal responsiveness of the studied varieties to using these preparations. Among the studied species, a considerable increase in productivity, as compared to the reference, was only observed in case of treating the domestic early-maturing Udacha variety with HB-101, while increased resistance to late blight was ensured by the Agat-25K preparation for the same variety. Thus, in the initial stages of the original seed production, the use of growth regulators with regard to varietal characteristics is a promising technique that makes it possible to increase productivity and quality of the meristematic material. Therefore, studying growth regulators is urgent at present, since each type of regulator should be studied individually, in relation to the varietal characteristics of the potato plants.

The research resulted in obtaining positive data about the effect of preparations like HB-101 on growth, development and productivity of potatoes. Data has also been obtained about the influence of the bio-fungicidal Agat-25K growth regulator on resistance to diseases, in particular to fungi disease in greenhouses. However, during these experiments we failed to study the effect of these preparations on the physiological and biochemical processes (photosynthesis, leaves assimilation area, peroxidase activity, biochemical indicators) of improved potatoes in the conditions of a greenhouse and the seed plot for cultivating domestic and imported varieties of various maturity classes. We are planning to perform these studies during the next vegetation season.

\section{ACKNOWLEDGMENTS}

The authors express their gratitude to the General Director of LLC “EliteKhoz" Anatoly Germanovich Puchkov for providing an experimental plot (biotechnology lab, greenhouse complex, improved potato plants) for the scientific research. 


\section{REFERENCES}

1. Anisimov, B.V., 2003. Current state and prospects in development of potato seed industry. Potatoes and Vegetables, 1: $27-30$.

2. Zasorina, E.V., K.L. Rodionov and K.S. Katunin, 2010. Reaction of potato varieties to the use of growth regulators in the Central Black Earth Region. The Bulletin of the Kursk State Agricultural Academy, 5: 50 - 51.

3. Lobachev, D.A. and V.S. Avdiyenko, 2010. The use of Epin-Extra in growing potatoes is effective. Potatoes and Vegetables, 1: 29.

4. Sekhon, H.S. and M. Singh, 1985. Effect of growth regulators and nitrogen on the growth, number and size of seed tubers and vield of potatoes. J. of Agr. Science, 104(1): 99 - 106. DOI: $10.10171 /$ S0021859600043033

5. Harmey, M.A., M.P. Growley and P.E. Clinch, 1966. The effect of growth regulators on tuberisation of cultured stem pieces of solanum tuberosum. European Potato Journal, 9(3): 146 - 151. DOI: 10.1007/BF02364301

6. Rai, A.K., A.K. Basu, G. Nilesh and P.C. Gupta, 2011. Studies on the Response of Growth Regulators and Number of Seedlings on Seed Quality of Rice (cv. Shatabdi). J. Interacad, 15(4): 530 - 534. ISSN 0971-9016

7. Cheremisin, A.I. and I.A. Yakimova, 2011. Influence of growth stimulants and biofungicides on the productivity of potato microplants. Achievements in Science and Technologies in the AIC, 3: 26 - 28.

8. Kozlov, A.V., 2013 Ecological assessment of diatomite influence on phytocoenosis and the state of the soil-biotic complex in light-grey forest light-loamy soils, abstract from thesis of a Candidate of Biological Sciences, the Russian State Agrarian University, Moscow.

9. Vakulenko, V.V., 2004. Growth regulators. Protection and Quarantine of Plants, 1: 24.

10. Zacharina, E.V. and I.Y. Pigorev, 2005. Potatoes growth regulators in the Central Black Earth Region. Agricultural Science, 7: $20-22$.

11. Ustimenko, I.F. and A.N. Postnikov, 2009. Efficacy of the zircon preparation in cultivation of potatoes. Achievements in Science and Technologies in the AIC, 4: 38 - 39.

12. Vert, G., J.L. Nemhauser, N. Geldner, F. Hong and J. Chory, 2005. Molecular mechanisms of steroid hormone signaling in plants. Annu Rev Cell Dev Biol., 21: 177 - 201. DOI: 10.1146/ 21.090704.151241
13. Zhu, J.K., 2002. Salt and drought stress signal transduction in plants. Annu Rev Plant Biol., 53: 247 - 273. DOI: 10.1146/53.091401.143329

14. Divi, U.K., T. Rahman and P. Krishna, 2010. Brassinosteroid - mediated stress tolerance in Arabidopsis shows interactions with abscisis acid, ethylene and salicylic acid pathways. BMC Pland Biology, 10: 151 - 164. DOI: 10.1186/ 1471-2229-10-151

15. Krishna, P., 2003. Brassinosteroid - mediated stress responses. J Plant Growth Regul, 22: 289 - 297. DOI: 10.1186/1471-2229-10-151

16. Kagale, S., U.K. Divi, J.E. Krochko, W.A. Keller and P. Krishna, 2007. Brassinosteroid confers tolerance in Arabidopsis and Brassica napus to a range of abiotic stresses. Planta, 225(2): 353 364. .DOI: 10.1186/1471-2229-10-151

17. Uskov, A.I., 2009. Reproduction of improved source material for potatoes seed industry: a rationale of the strategy. Achievements in Science and Technologies in the AIC, 6: 30 - 33.

18. Orlov, A.N., 2004. Yield and quality of tubers depending on the use of growth regulators. Actual problems of agriculture at present stage of agriculture development. The Penza Agricultural Academy, pp: 82 - 83.

19. Bobrik, A.O., 2001. Efficiency of using biologically active substances in primary potatoes seed industry. Issues of Potato Cultivation. VNIIKH, pp: $289-292$.

20. Tarazanova, T.V. and N.N. Ignatiev, 2013. The effect of bio-stimulant on yield formation and the quality of potatoes. The Agrochemical Bulletin, 3: 24-27. ISSN 0022-9148.

21. Kirdey, T.A. and D.A. Belyaeva, 2012. Growth regulators increase yield and quality of tubers. Potatoes and Vegetables, 3: 13.

22. Petrov, V.B., V.K. Chebotar and A.E. Kozakov, 2002. Microbiological preparations in biologization of agriculture in Russia. Achievements in Science and Technologies in the AIC, 10: 12 - 15.

23. Rex, B.L., 1992. Effect of two plant growth regulators on the yield and quality of russet Burbank potatoes. Potato Research, 35(3): 227 - 233. DOI: 10.1007/BF02357703

24. Dospekhov, B.A., 1985. Methods of experiments Moscow: Agropromizdat, pp: 2130. ISBN 5-9532-0029-3.

25. Uromova, I.P., 2009. Agrobiological and ecological rationale for the methods of cultivating the potatoes obtained by the method of apical meristem, in the conditions of the Volga-Vyatka region, $\mathrm{PhD}$ thesis, BAA, Bryansk. 
26. Bari, R. and J.D. Jones, 2009. Role of plant hormones in plant defence responses. Plant Mol Biol., 69: 473 - 488. DOI: 10.1007/ S11103008-9435-0

27. Uromova, I.P., O.V. Shtyrlina, N.N. Koposova, A.V. Kozlov and D.A. Shtyrlin, 2014. Brassinosteroids in breeding Technologies healthcare Potato. American Journal of Agricultural and Biological Sciences, 9: 445-449.
DOI: 10.3844/ajabssp.2014.445.449 ISSN: 1557-4989

28. Kotikov, V.M., 2011. Peculiarities of protecting various potato varieties against phytophthora rot. Protection and Quarantine of Plants, 5: 27 - 28.

29. Filippov, A.V., 2005. Potatoes phytophthora rot. Protection and Quarantine of Plants, 4: 74.

30. Uromova, I.P., 2009. Yield and quality after using biologic preparations. Fertility, 1: 33. 